\title{
Science Training for Journalists: An Essential Tool in the Post-Specialist Era of Journalism
}

\author{
Sunshine Menezes* \\ Metcalf Institute for Marine \& Environmental Reporting, Natural Resources Science, University of Rhode Island, Kingston, RI, \\ United States
}

\section{OPEN ACCESS}

Edited by:

Bridie McGreavy,

University of Maine, United States

Reviewed by:

Ana K. Houseal,

University of Wyoming, United States

Shawn Kyle Davis,

Slippery Rock University of

Pennsylvania, United States

*Correspondence: Sunshine Menezes sunshine@uri.edu

Specialty section:

This article was submitted to Science and Environmental Communication, a section of the journal Frontiers in Communication

Received: 11 November 2017 Accepted: 12 January 2018 Published: 30 January 2018

Citation:

Menezes S (2018) Science Training for Journalists: An Essential Tool in the Post-Specialist Era of Journalism.

Front. Commun. 3:4.

doi: 10.3389/fcomm.2018.00004
A majority of US adults are concerned about a rise in misinformation regarding current issues and events. The spread of inaccurate information via social media and other sources has coincided with a massive transition in the news industry. Smaller newsrooms now have fewer journalists, and their responsibilities have shifted toward producing more stories, more quickly, while contributing to their outlets' blogs and social media feeds. Lean newsroom budgets also eliminated in-house professional development for journalists, making external training programs an essential vehicle for reporters and editors to gain new content knowledge, sources, and skills in a constantly evolving news landscape. The loss of specialized beat reporters in many newsrooms since the mid-2000s has made training especially critical for journalists covering complex, science-based topics such as climate change and public health. In the USA, relatively few organizations offer science training opportunities for journalists, but the need and demand for these programs are growing as newsrooms increasingly rely on generalist reporters to cover a wide range of scientific topics. This perspective summarizes the challenges that non-specialist reporters face in covering science-based stories and describes a successful training model for improving science and environmental news coverage to yield reporting that is not only accurate but also offers the nuance and context that characterizes meaningful journalism.

Keywords: journalism, training, professional development, science journalism, environmental journalism, science communication, environmental communication

Americans have been bombarded with claims of "fake news" since November 2016, when Donald Trump began to reference the term following the US presidential election. The term had previously been used to refer to satirical television comedies such as "The Daily Show" and "The Colbert Report" that used a faux-journalistic format (Borden and Tew, 2007). As of late 2016, however, "fake news" became part of the cultural zeitgeist in the USA, inspiring responses ranging from comedians' punch lines to rumor-based vigilantism (Fisher et al., 2016).

The purposeful spread of inaccurate information is nothing new, but a wide range of people have become concerned about fake news. In a December 2016 poll by the Pew Research Center (2016c), $64 \%$ of US adults reported feeling that "fabricated news stories cause a great deal of confusion about the basic facts of current issues and events." In this same survey, $84 \%$ of respondents reported feeling somewhat to very confident in their ability to detect fake news.

Their confidence seems at odds with the continuous spread of misinformation (Chan et al., 2017). This has become a more pernicious problem in the era of social media, when anonymity 
and a much-accelerated version of the old-fashioned rumor mill (Zubiaga et al., 2016) allow misinformation to be spread easily, quickly, and without fear of repercussion. The freedom to spread false information on social media is exacerbated by broader communication challenges related to cognitive bias, motivated reasoning, and increasingly deep identity divides along socio-economic, political, and/or cultural lines (Kahan, 2015; Flynn et al., 2017). Selective exposure to specific information sources may be another culprit (Boxell et al., 2017; Schmidt et al., 2017). As a result, people experience a daily flood of information that may or may not be accurate. Often, individuals are left to determine the legitimacy of this information on their own, through the disparate lenses of their own biases.

Against this backdrop, public discourse about environmental issues, especially climate change, has become a political minefield (Painter, 2013; Kahan, 2015) in which science is often perceived as just another opinion, rather than a foundation for discussion about policy options and practical solutions.

\section{CHALLENGES FOR JOURNALISTS COVERING ENVIRONMENTAL TOPICS}

How can we address this misinformation dilemma? What are the mechanisms for increasing access to accurate, objective information and facilitating informed public discourse on critical environmental issues?

There is no single answer to these questions, but one important piece of the solution is to ensure that news coverage is not only accurate but also clear and properly contextualized. News coverage remains influential in setting public agendas regarding what news consumers talk about and how policy makers respond, especially with regard to environmental issues (Dunwoody and Peters, 1993; Boykoff and Yulsman, 2013; Hansen, 2015). Unfortunately, the journalism industry has suffered significant losses since the mid-2000s (Friedman, 2015; Pew Research Center, 2016a), resulting in newsrooms whose reporting staff bring a much reduced breadth of expertise (Pew Research Center, 2013). The expectations of journalism in the era of social media pose another challenge to producing nuanced reporting. In many newsrooms, smaller reporting staffs' expanded reporting duties are compounded by the requirements for crafting multiple blog and/or social media posts each day (Friedman, 2015).

The challenge of providing news coverage that is simultaneously accurate, contextualized, and compelling is especially salient with regard to environmental stories. Massive newsroom layoffs affected mainstream news outlets' science and environment coverage significantly, eliminating many of these specialty beats (Bagley, 2013) and/or shifting these stories to less experienced reporters who function as generalists, rather than specialists (Crow and Stevens, 2012; Boykoff and Yulsman, 2013). Environmental coverage is complicated by its necessary mixture of science, policy, and personal opinion. Reporters must navigate scientific research, sorting out areas of consensus and debate, and weigh scientific perspectives along with those of affected communities and political agendas. As news outlets have moved toward distributing, or "mainstreaming," environmental stories across the newsroom (Friedman, 2015), and assigning these stories to non-specialists, the quality of scientific content has suffered for a number of reasons.

First, very few US journalists bring a science background to their work. Sachsman et al. (2008) reported that $3 \%$ of US journalists had an undergraduate major in science. This is not a hindrance for all types of news coverage, but it is unrealistic to expect a reporter whose last formal experience with science may have come from high school or a single college course to identify the nuances in a scientific debate or recognize the larger environmental context that might be relevant to a particular story. Furthermore, a limited facility and confidence with probabilities and statistics among many journalists makes it difficult or impossible for them to critically analyze scientific claims and the risks of action or inaction (Painter, 2015). In two surveys of journalism school administrators spanning 1997-2008, only 25\% thought their students received sufficient statistical instruction, leading the study authors to describe training in statistical reasoning as the "castor oil of journalism pedagogy" (Dunwoody and Griffin, 2013). Without these educational foundations, it is much easier to produce stories focusing on political debate or drama related to environmental issues (Boykoff and Yulsman, 2013), or to simply report two opposing viewpoints, than it is to produce illuminating reporting that accurately translates areas of scientific consensus and debate. Nisbet and Fahy (2015) described this as a process leading to journalism "dominated by voices representing the tail ends of opinion."

Second, environmental stories are inherently complex and, therefore, time intensive. Depending on the audience, a single story about the effects of sea level rise on a coastal community in Rhode Island, for example, could be informed by researchers studying rates of glacial melting in the Arctic, loss of coastal wetlands in southern New England, coastal engineering, and economic effects on tourism-reliant businesses, in addition to community members and government officials. While this diverse blend of sources could lead to an informative and wellcontextualized story, it would also require more time for reporting and an ability to weave the science and engineering background in with the political and personal perspectives. It is not surprising that a reporter without a science background, in a newsroom that expects multiple stories to be filed each day, might default to a one- or two-source story lacking broader context and insights (Gibson et al., 2016).

Third, scientists' ineffective communication styles impede clear summaries of their work. Academics' use of jargon, as well as their reticence to comment on the broader significance of their research (or even speak with a reporter), can make it difficult or impossible to use their quotes or insights within a news story. It is easy for a journalist who lacks a familiarity with the process and culture of science to be swayed by the clear and compelling, but not necessarily accurate, arguments of a politician, activist group, or a vocal community member.

This is certainly not a complete list: framing, editorial disinterest, media ownership, and many other issues could be added to the list of complicating factors for environmental reporting (Boykoff and Yulsman, 2013; Anderson, 2015). As a result of the specific challenges identified here, however, journalists who are 
new to covering science-based stories, or who do so only on occasion, are at a distinct disadvantage, for which news consumers pay the price.

\section{SCIENCE TRAINING FOR JOURNALISTS}

Training journalists to become more discerning translators of scientific information is one mechanism for addressing these challenges. This type of professional development can build journalists' understanding of scientific methods and uncertainty and help them place environmental stories within a broader scientific context, giving news audiences a much richer suite of information from which to form their opinions.

The University of Rhode Island's Metcalf Institute for Marine \& Environmental Reporting has conducted 54 science trainings for journalists since 1999. Over this time, Metcalf training has evolved to accommodate the needs, interests, and time constraints of professional journalists. The Institute currently offers a range of programs that allow more comprehensive learning over the course of a week, intensive 1-2 days science seminars that explore the science underlying specific environmental topics, conference-based programs that provide brief introductions to issues, and webinars that expose participants to individual speakers with expertise in environmental science, policy, and/or communication.

Metcalf Institute's Annual Science Immersion Workshop for Journalists provides a rare deep-dive into the process of conducting scientific research. The Annual Workshop Fellowship introduces journalists to the science of global change with a focus on coastal ecosystems. The hands-on experiences in the lab, field, and classroom give Annual Workshop Fellows a greater familiarity with environmental science and access to a wide range of sources and scientific resources. The most important objectives are more fundamental, however. The Workshop facilitates off-deadline conversations between scientists and journalists that explore the slow, iterative process of research; explain how researchers work to minimize and manage scientific uncertainty; and build mutual understanding about the cultures and norms of both science and journalism. These interactions between journalists and scientists and also among the journalist Fellows change participants' approaches toward reporting on science-based topics (Smith et al., 2017), while helping participating scientists hone their own communication skills.

The demand for this type of training is significant. Metcalf Institute typically receives more than 100 applications for the 10 available Annual Workshop fellowship spots. A growing number of applicants are based outside of the USA, often in developing nations where journalism training is scarce and training related to environmental reporting is even harder to come by. Many of these applicants live in places where environmental issues are an essential underpinning of socio-political concerns, yet the environment receives minimal or no coverage.

Interest in the shorter science seminars for journalists is also intense, attracting applicants from across the USA, from large and small news outlets and from all media types. In short, there is a substantial demand for journalist training on environmental issues that, in spite of the best efforts of Metcalf Institute and a small band of other programs with similar goals, is not being met.

These professional development opportunities for journalists are essential in a constantly evolving news landscape. Newsrooms no longer provide the training or in-house resources that once supported the development of novice reporters and advanced the capacity of more experienced reporters. Meanwhile, environmental challenges - and their solutions - are growing apace, driving a largely unmet demand for environmental news coverage (Miller and Pollak, 2012).

Yet, funding for this type of training has become ever more challenging. While many organizations and individuals lament the superficial or insufficient news coverage of environmental issues, relatively few funders have stepped forward to provide substantive or consistent support for journalist training in this arena. In addition, there has been an expectation in recent years from some foundation funders that journalist training programs must result in a specified number of news stories by participants. This runs counter to the approach taken by Metcalf Institute and most of its sister organizations. These training programs always yield stories, but the Institute does not simply seek an output of " $\mathrm{x}$ stories per participant" after a training. Rather, Metcalf's goal is to change participants' approaches toward covering science-based stories for the rest of their careers.

Analyses of Metcalf training based on pre- and post-training self-efficacy surveys, content analysis, and interviews indicate that this more ambitious and long-term approach is effective. A study of Annual Science Immersion Workshop alumni showed positive changes in efficacy related to their confidence in covering scientific issues, understanding of how scientists conduct research, and ability to discern the credibility of scientific sources (Smith et al., 2017). This study also found a domino effect of Metcalf training, with $90 \%$ of survey respondents reporting that they had shared information from their training experience with colleagues. Finally, pre- and post-training analyses of participants' reporting showed changes in their framing of environmental topics, with post-training stories offering a broader scientific context and more frequent references to scientific uncertainty.

Clearly, science training for journalists can address some of the barriers journalists face when covering environmental topics. This training has become far more essential as environmental coverage has shifted away from specialist reporters, especially in non-elite newsrooms that serve smaller local and regional audiences.

\section{LEARNING FROM EXPERIENCE}

For many years, the Annual Science Immersion Workshop for Journalists was designed to give participants a better understanding of scientific principles through personal experience: guiding them through an accelerated tour of "a day in the life of a coastal scientist," from hypothesis generation to data collection and data analysis. This approach changed journalists' perspectives, helping them to understand the deliberation and iteration that characterize scientific research. Interviews conducted by Smith et al. (2017), however, revealed that some participants were more interested in the big picture than in the details of data collection 
or analysis. Specifically, interviewees noted the benefits of gaining a better sense of the "humanity" of scientists through their interactions at the Workshop and learning from scientists how to critically evaluate scientific publications.

Metcalf Institute adapted the Annual Workshop in response to the Smith et al. study. The program still offers an intense dive into global change science with a focus on coastal zones, but the activities are designed to offer more applied experiences that prepare trainees to approach any scientific topic with greater discernment and confidence.

In practice, this programmatic shift translates to a more explicit and iterative examination of topics that many reporters struggle to convey, e.g., scientific uncertainty, probabilities and statistics, and data visualization. The Workshop also features more interactive co-learning opportunities, such as role-play exercises and "shop talk" sessions that allow journalists and scientists to discuss how the Fellows might apply their new knowledge and skills to specific challenges they face in their reporting. While science still takes center stage in the program, it is supported by activities and interactions that encourage participants to question their approaches toward covering these topics. Critically, the experience also builds journalists' confidence in asking questions about scientists' research motivations and conclusions-information that can enrich participants' reporting on a range of topics.

\section{TRAINING AS A TOOL FOR OPTIMIZING THE POST-SPECIALIST ERA}

Some have called for a turn toward "knowledge-based journalism," which would apply specialized expertise in relevant natural and social science to improve reporting related to both the content and process of public affairs issues such as the environment (Patterson, 2013; Donsbach, 2014; Nisbet and Fahy, 2015). This ideal and especially the approaches identified by Nisbet and Fahy (2015) for achieving it are worth striving for and cultivating. Yet, there are far more non-specializing journalists covering environmental stories today than there are specialists and the news industry needs ways to improve the coverage produced by

\section{REFERENCES}

Anderson, A. (2015). "News organization(s) and the production of environmental news," in The Routledge Handbook of Environment and Communication, eds A. Hansen and R. Cox (New York, NY: Routledge), 175-183.

Bagley, K. (2013). About a Dozen Environment Reporters Left at Top 5 U.S. Papers. InsideClimate News. New York, NY. Available at: https://insideclimatenews. org/news/20130114/new-york-times-dismantles-environmental-deskclimate-change-global-warming-journalism-newspapers-hurricanesandy

Borden, S., and Tew, C. (2007). The role of journalist and the performance of journalism: ethical lessons from "fake" news (seriously). J. Mass Media Ethics 22, 300-314. doi:10.1080/08900520701583586

Boxell, L., Gentzkow, M., and Shapiro, J. M. (2017). Is the Internet Causing Political Polarization? Evidence from Demographics, NBER Working Paper, No. 23258. Available at: http://www.nber.org/papers/w23258

Boykoff, M. T., and Yulsman, T. (2013). Political economy, media, and climate change: sinews of modern life. WIREs Clim. Change 4, 359-371. doi:10.1002/wcc.233

Chan, M.-P. S., Jones, C. R., Jamieson, K. H., and Albarracín, D. (2017). Debunking: a meta-analysis of the psychological efficacy of messages this larger, inexpert group. Local news outlets, for example, are highly unlikely to be able to accommodate the knowledge-based journalism approach, yet these outlets play a significant role in public discussion within their target constituencies (King et al., 2017). Reich and Godler (2016) offered a potent critique of this debate when they argued that it is "more urgent to develop novel ways to optimize and cope with non-specialization rather than to lament its arrival."

Larger, well-funded news outlets and smaller non-profit outlets will likely maintain some degree of specialized reporting on the environment. However, it is equally-and perhaps more (Pew Research Center, 2016b; King et al., 2017)_important to ensure reporters at smaller, local news outlets have received sufficient training to build a basic fluency with the fundamental assumptions, limitations, and norms of scientific research and the confidence to pursue science-based stories. Metcalf Institute's outcomes demonstrate that training via professional development is an effective tool for optimizing the science reporting skills of specialists and non-specialists, alike.

Journalism has played an essential role in public discourse for hundreds of years. As the industry continues its search for a successful, sustained business model in the Internet Age, the demands upon individual journalists and the public need for substantive reporting that counters misinformation continue to grow. In the meantime, newsrooms and journalism funders must use the available tools to facilitate the best possible journalism. A more widespread commitment to journalists' ongoing professional development is an essential step in this process.

\section{AUTHOR CONTRIBUTIONS}

SM is the sole author of this work. Any correspondence should be sent to her.

\section{FUNDING}

The author has not received any funding for this perspective paper.

countering misinformation. Psychol. Sci. 28, 1531-1546. doi:10.1177/ 0956797617714579

Crow, D. A., and Stevens, J. R. (2012). Local science reporting relies on generalists, not specialists. Newspap. Res. J. 33, 35-48. doi:10.1177/ 073953291203300303

Donsbach, W. (2014). Journalism as the new knowledge profession and the consequences for journalism education. Journalism 15, 661-677. doi:10.1177/ 1464884913491347

Dunwoody, S., and Griffin, R. J. (2013). Statistical reasoning in journalism education. Sci. Commun. 35, 528-538. doi:10.1177/1075547012475227

Dunwoody, S., and Peters, H. P. (1993). “The mass media and risk perception," in Risk as a Construct, ed. B. Ruck (Munich: Knesebeck), 293-317.

Fisher, M., Cox, J. W., and Hermann, P. (2016). Pizzagate: From Rumor, to Hashtag, to Gunfire in D.C. Washington, DC: Washington Post. Available at: https://www.washingtonpost.com/local/pizzagate-from-rumor-to-hashtagto-gunfire-in-dc/2016/12/06/4c7def50-bbd4-11e6-94ac-3d324840106c_story. html?utm_term $=0.295 f 2 b b 36990$

Flynn, D. J., Nyhan, B., and Reifler, J. (2017). The nature and origins of misperceptions: understanding false and unsupported beliefs about politics. Adv. Pol. Pyschol. 38, 127-150. doi:10.1111/pops.12394 
Friedman, S. (2015). “The changing face of environmental journalism in the United States," in The Routledge Handbook of Environment and Communication, eds. A. Hansen and R. Cox (New York, NY: Routledge), 143-155.

Gibson, T. A., Criag, R. T., Harper, A. C., and Alpert, J. M. (2016). Covering global warming in dubious times: environmental reporters in the new media ecosystem. Journalism 14, 417-434. doi:10.1177/1464884914564845

Hansen, A. (2015). "News coverage of the environment: a longitudinal perspective," in The Routledge Handbook of Environment and Communication, eds A. Hansen and R. Cox (New York, NY: Routledge), 208-215.

Kahan, D. M. (2015). Climate science communication and the measurement problem. Adv. Pol. Psychol. 36, 1-43. doi:10.1111/pops.12244

King, G., Schneer, B., and White, A. (2017). How the news media activate public expression and influence national agendas. Science 358, 776-780. doi:10.1126/ science.aaol100

Miller, T., and Pollak, T. (2012). Environmental Coverage in the Mainstream News: We Need More. Project for Improved Environmental Coverage. SEE Innovation, 24. Available at: https://climateaccess.org/system/files/PIEC_Environmental\%20 Coverage.pdf

Nisbet, M., and Fahy, D. (2015). The need for knowledge-based journalism in politicized science debates. Ann. Am. Acad. Polit. Soc. Sci. 658, 223-234. doi:10.1177/0002716214559887

Painter, J. (2013). Climate Change in the Media. London: I.B. Tauris \& Co. Ltd. In Association with the Reuters Institute for the Study of Journalism, University of Oxford.

Painter, J. (2015). Taking a bet on risk. Nat. Clim. Change 5, 286-288. doi:10.1038/ nclimate 2542

Patterson, T. E. (2013). Informing the News: The Need for Knowledge-Based Journalism. New York, NY: Vintage.

Pew Research Center. (2013). The State of the News Media 2013. Available at: http://assets.pewresearch.org.s3.amazonaws.com/files/journalism/State-ofthe-News-Media-Report-2013-FINAL.pdf

Pew Research Center. (2016a). The State of the News Media 2016. Available at: http:// assets.pewresearch.org/wp-content/uploads/sites/13/2016/06/30143308/stateof-the-news-media-report-2016-final.pdf
Pew Research Center. (2016b). Civic Engagement Strongly Tied to Local News Habits. Available at: http://www.journalism.org/2016/11/03/civic-engagementstrongly-tied-to-local-news-habits/

Pew Research Center. (2016c). Many Americans Believe Fake News Is Sowing Confusion. Available at: http://www.journalism.org/2016/12/15/many-americansbelieve-fake-news-is-sowing-confusion/

Reich, Z., and Godler, Y. (2016). "The disruption of journalistic expertise," in Rethinking Journalism Again: Societal Role and Public Relevance in the Digital Age, eds C. Peters and M. Broersma (New York, NY: Routledge), 64-81.

Sachsman, D. B., Simon, J., and Valenti, J. M. (2008). Enviornment reporters and U.S. journalists: a comparative analysis. Appl. Environ. Educ. Commun. 7, 1-19. doi:10.1080/15330150802194862

Schmidt, A. L., Zollo, F., Del Vicario, M., Bessi, A., Scala, A., Caldarelli, G., et al. (2017). Anatomy of news consumption on Facebook. Proc. Natl. Acad. Sci. U.S.A. 114, 3035-3039. doi:10.1073/pnas.1617052114

Smith, H., Menezes, S., and Gilbert, C. (2017). Science training and environmental journalism today: effects of science journalism training for early to midcareer professionals. J. Appl. Environ. Educ. Commun. 1-13. doi:10.1080/1533015X. 2017.1388197

Zubiaga, A., Liakata, M., Procter, R., Wong Sak Hoi, G., and Tolmie, P. (2016). Analysing how people orient to and spread rumours in social media by looking at conversational threads. PLoS ONE 11:e0150989. doi:10.1371/journal.pone.0150989

Conflict of Interest Statement: The author declares that the research was conducted in the absence of any commercial or financial relationships that could be construed as a potential conflict of interest.

Copyright $\odot 2018$ Menezes. This is an open-access article distributed under the terms of the Creative Commons Attribution License (CC BY). The use, distribution or reproduction in other forums is permitted, provided the original author(s) and the copyright owner are credited and that the original publication in this journal is cited, in accordance with accepted academic practice. No use, distribution or reproduction is permitted which does not comply with these terms. 